\title{
47. ELECTRICAL RESISTIVITY OF BASALTS, LEG 34
}

\author{
M.J. Drury, Department of Oceanography, Dalhousie University, Halifax, Nova Scotia, Canada
}

\section{INTRODUCTION}

It is becoming increasingly evident that the physical properties of continental basalts, which have been studied in some detail, are not representative of corresponding properties of deep ocean-floor rocks. The Deep Sea Drilling Project provides a unique opportunity to obtain and study ocean crust rocks in detail. In situ measurements have provided, by means of both natural and artificial sources, information on such geophysical parameters as seismic wave velocities, heat flow, and electrical resistivity. Chemical analyses of deep ocean basalts have shown that the minor element compositions and alteration processes are not typical of corresponding continental basalts (e.g., Hart, 1973), and special relationships between the geology and geophysics of oceanic layer II have been demonstrated, such as the decrease in seismic velocities with progressive alteration (e.g., Christensen and Salisbury, 1972). The electrical resistivity of oceanic basalts from DSDP Leg 26 (Indian Ocean) has also been studied (Hyndman and Ade-Hall, 1974) at simulated in situ conditions, and the basalts have been shown to have generally much lower resistivities than continental basalts under the same conditions. Those authors suggested that a strong correlation between Curie temperature (and hence degree of cation deficiency in titanomagnetite) and resistivity indicated that secondary hematite (observed with the microscope) was providing conduction paths within the samples, thereby lowering the resistivity. These observations of generally low resistivity of oceanic basalts substantiated the results of several deep ocean-floor magnetotelluric surveys (Cox et al., 1970; Greenhouse, 1972; Richards, 1970), each of which suggested that lower resistivities occur beneath the sea floor than generally exist beneath continents. Although the electrical resistivity of most rocks decreases rapidly with increasing temperature, it appears that the low electrical resistivity beneath the sea floor cannot be explained in terms of elevated temperatures for continental basaltic and ultramafic rocks of the kind normally studied in the laboratory (Cox et al., 1970).

A large number of measurements of electrical resistivity of basalts at oceanic crustal temperatures and pressures $\left(0^{\circ}-100^{\circ} \mathrm{C}, 0.5-2 \mathrm{~kb}\right)$ has been made. Since most rocks are likely to be saturated with aqueous solutions to at least $5 \mathrm{~km}$ depth (Brace, 1971), only resistivity values for rocks under such conditions will be relevant. Under sea-floor conditions of saturation, temperature, and pressure, most subaerial gabbros and basalts studied have resistivities in the range $10^{4}-10^{5} \mathrm{ohm}-\mathrm{m}$ (e.g., Keller, 1966; Brace and Orange, 1968; Stesky and Brace, 1973; Hermance et al., 1972). In contrast, deep ocean-floor samples dredged from the Indian Ocean have significantly lower resistivities of $10^{2}-2 \times 10^{3} \mathrm{ohm}$ - m (Cox, 1971; Stesky and Brace, 1973). The geometric mean resistivity of the DSDP samples studied by Hyndman and Ade-Hall (1974) is $140 \mathrm{ohm}-\mathrm{m}$, and of 25 samples from Legs 2-6 and 11-14 is $170 \mathrm{ohm}-\mathrm{m}$ (M.J. Drury, unpublished data).

\section{RESISTIVITY AND POROSITY MEASUREMENTS}

Resistivity measurements were made in a manner very similar to that described by Hyndman and Ade-Hall (1974). The samples from Leg 34 were in the form of cylinders $2.5 \mathrm{~cm}$ in diameter and about $5 \mathrm{~cm}$ long. The ends were painted with silver-filled conducting epoxy resin, and the sample was held between two stainless steel electrodes. Both sample and electrodes are encased in an impervious rubber jacket to exclude the hydraulic fluid pressure medium. The sample face of each electrode is perforated with holes leading to reservoirs to take up pore water squeezed from the samples, so that the pore pressure should be hydrostatic, and hence lower than the confining pressure. Measurements were made at a single frequency of $10 \mathrm{~Hz}$, which should be high enough to prevent induced polarization effects, and low enough to prevent capacitive effects. The possible conduction mechanism can be determined from observation of several parameters such as pressure, temperature, frequency, porosity, and the difference in resistivity when the sample is dry or water saturated. The dependence of resistivity was measured for each of these parameters except frequency. Since the pore-fluid pressure is hydrostatic (determined by the pressure of water head assuming all pores and cracks are interconnected to the surface) and the confining pressure lithostatic (determined by the weight of overlying rock), the configuration simulates in situ conditions.

Brace et al. (1965) and Brace and Orange (1968) have argued that a large positive increase in resistivity with increasing pressure shows that the conduction mechanism is primarily ionic, through the electrolytic pore fluids. Increasing the pressure closes off conducting paths, increasing the resistivity. A small or negative pressure effect, on the other hand, indicates primarily mineral conduction; increasing the pressure brings the conducting grains into more intimate contact. A strong exponential decrease in resistivity with temperature also suggests mineral semiconduction, the conductivity being given by

$$
\sigma=\sigma_{o} e^{-\mathrm{E} / \mathrm{kT}}
$$

where $\sigma_{o}$ is the high temperature conductivity asymptote (a measure of the total number of charge carriers that can be activated), $E$ is the activation energy for the charge carriers, $k$ is Boltzman's constant, and T is the absolute temperature. The dependence of resistivity of a 
saturated rock on its porosity has been reported by many authors. Brace et al., (1965) found that for continental rocks in which pore-fluid conduction was the primary mechanism, the pore porosity $\eta$, rock resistivity $\rho_{\mathrm{s}}$, and saturating fluid resistivity $\rho_{\mathrm{a}}$, are related by the equation

$$
\rho_{s}=\rho_{o} \eta^{-2}
$$

In general terms, this expression (Archie's law) can be written $\rho_{S}=A \rho_{o} \eta^{-m}$, where $A$ is approximately unity, $m$ is approximately 2 for a very wide range of different types of rock, and $\eta$ is now the total effective porosity consisting of both pore and crack porosity. Related to the porosity-resistivity relationship for a rock is the ratio of dry resistivity to saturated resistivity. If mineral conduction is the primary mechanism, this ratio is expected to be low; whereas if electrolytic pore-fluid conduction dominates, the ratio will be high.

The effects of pressure, porosity, and the dry: saturated resistivity ratio emphasize the necessity for obtaining complete saturation of the samples. Brace and Orange (1968, fig. 3) demonstrate how only partial saturation could lead to the erroneous impression that pore-fluid conduction is unimportant, since increasing pressure closes off some cracks and pores and effectively saturates a sample which at atmospheric pressure is only partially saturated. The saturation procedure for the Leg 34 samples is lengthy, but should provide complete saturation (R.D. Hyndman, personal communication). The samples are placed in vacuo for a few hours and partially saturated by immersion while still under vacuum, then completely saturated under $1 \mathrm{~kb}$ pressure for several hours. The saturating fluid is distilled water, since original salt will remain in the rock during drying, and hence saturating in seawater will increase the salinity of the pore fluids over that expected for at least upper oceanic crustal aqueous solutions. The resistivity of the pore fluid is then about $0.30 \mathrm{ohm}-\mathrm{m}$. Samples are subsequently stored in seawater to prevent diffusion of the salts out from the rock. The drying procedure for porosity determinations is also lengthy, since drying is surprisingly slow (R.D. Hyndman, personal communication). The samples were dried under vacuum at $70^{\circ}$ $75^{\circ} \mathrm{C}$ for $72 \mathrm{hr}$, and stored in a desiccator at room temperature. Subsequent dry rock measurements (weighing and resistivity determination) must be performed quickly since on exposure to the atmosphere, the rock absorbs moisture rapidly, due to the salt content. Since all such measurements were performed in a time period of less than $1 \mathrm{~min}$, it is felt that no serious error will ensue.

Resistivity as a function of pressure to $2 \mathrm{~kb}$ and temperature dependence to $50^{\circ} \mathrm{C}$ were measured. Intervals of at least $4 \mathrm{hr}$ between successive pressure measurements are required to allow the effects of adiabatic heating or cooling resulting from pressure changes to dissipate. For temperature determinations, the pressure vessel was heated externally by a copper coil connected to a water bath and temperatures measured internally by a thermistor. Temperature measurements have an accuracy of about $\pm 0.1^{\circ} \mathrm{C}$ and pressure measurements of about $\pm 2 \%$. Resistivity values were found to be reproducible to within $5 \%$. Usually, there is a small difference in resistivity at the same pressure for increasing and decreasing pressure. The average is presented.

Porosity measurements were made by weighing the samples when dry and when saturated, as described in Boyce (1973). A small correction for residual salt left after drying was applied. The estimated accuracy of porosity measurements is $\pm 2 \%$ of the porosity value.

\section{RESISTIVITY RESULTS AND DISCUSSION}

Resistivity as a function of pressure is shown in Figure 1. All samples show a small positive pressure effect suggesting that pore-fluid conduction is important in the samples, as described above. The more rapid initial increase (to about $0.5 \mathrm{~kb}$ ) in resistivity of the three least-resistive samples is probably due to the closing of microcracks introduced into the samples by the mechanical and thermal stresses of drilling. The lower, and steadier, rate of increase of resistivity with increasing pressure above about $0.5 \mathrm{~kb}$ suggests that all such cracks are closed above this confining pressure.

The temperature dependence, on the other hand, shows a linear decrease of $\log$ resistivity against reciprocal absolute temperature (Figure 2), suggesting a semiconduction mechanism. The calculated activation energies of $0.20 \mathrm{ev}$ for Sample 321-14-3 and $0.27 \mathrm{ev}$ for

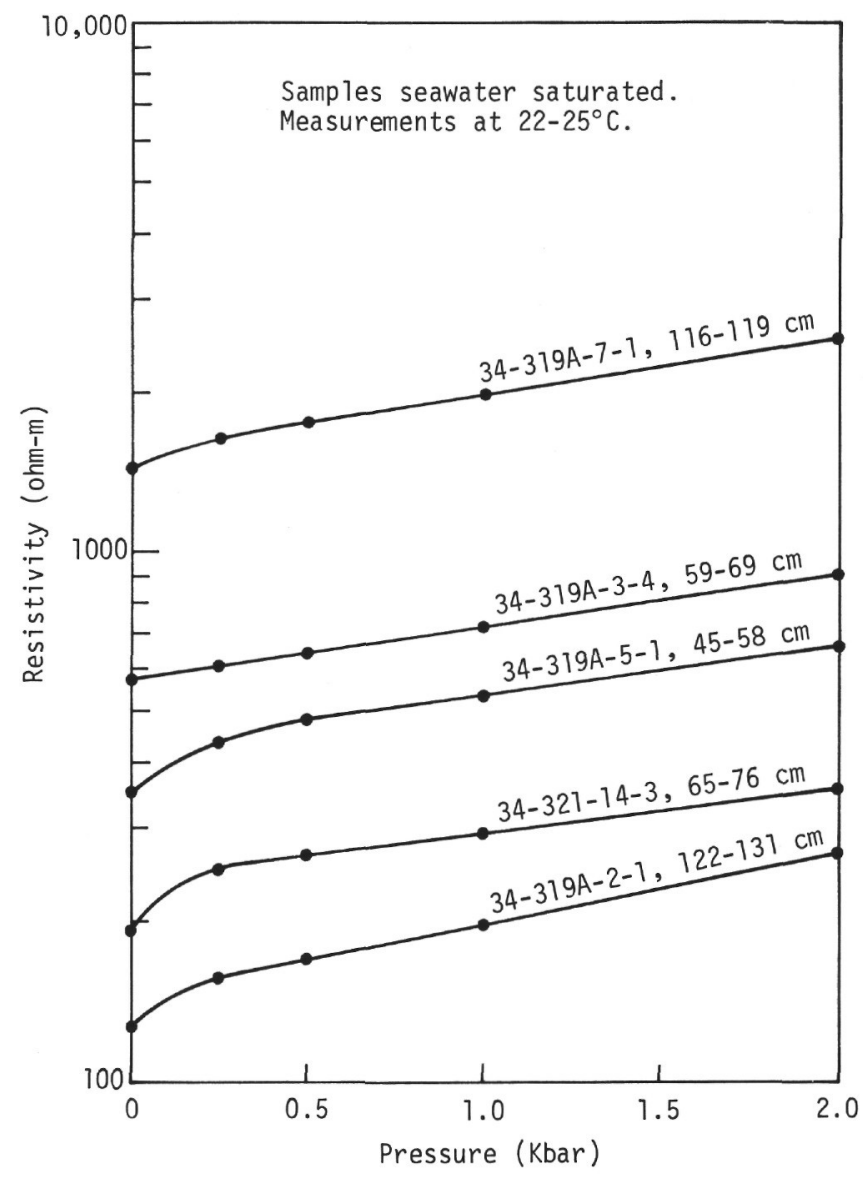

Figure 1. Resistivity of five Leg 34 basalts as a function of pressure at $22^{\circ}-25^{\circ} \mathrm{C}$. 


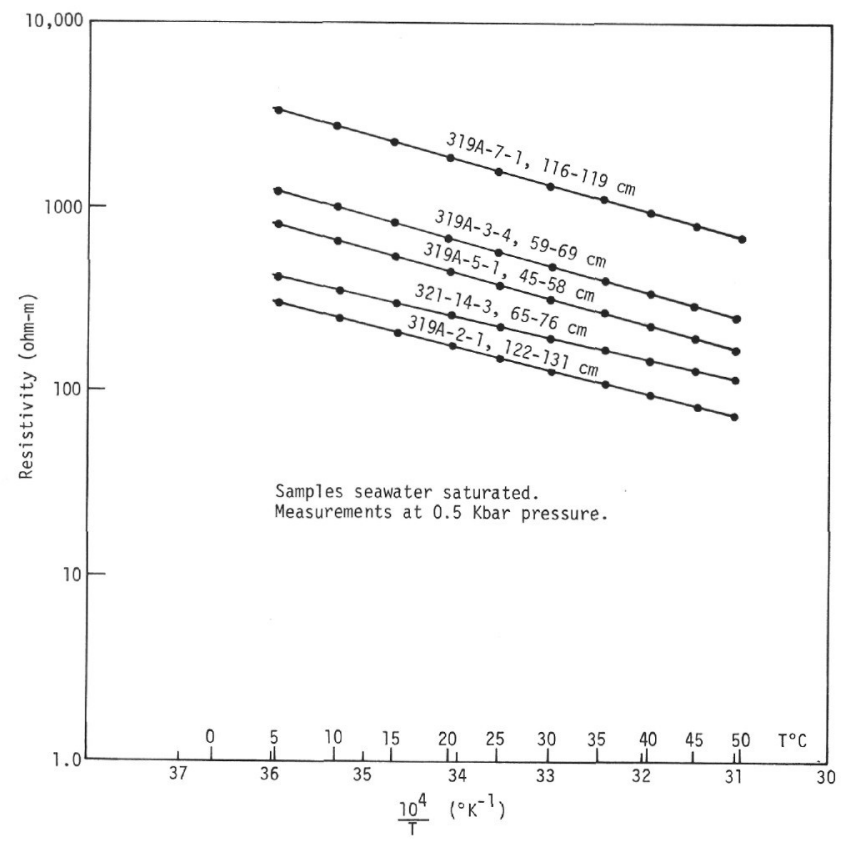

Figure 2. Resistivity of Leg 34 samples as a function of temperature at $0.5 \mathrm{~kb}$ presisure.

the Hole 319A samples are low, suggesting impurity semiconduction (e.g., Coster, 1948; Hamilton, 1965). The observed temperature dependence suggests that mineral grain conduction is also important in the samples.

Figure 3 shows the relationship between total effective porosity (interconnected cracks and rounded pores) and resistivity at atmospheric pressure. The line DSDP 2-14 is the least-squares fit to 25 samples from Legs 2 through 6 and 11 through 14. The curve BOM is the Brace et al. (1965) relationship between pore porosity and resistivity at $4 \mathrm{~kb}$ pressure, and although not entirely relevant to this discussion, is shown for reference. The Leg 34 samples and the Leg 26, Site 257, samples shown as comparison fall significantly off the DSDP 2-14 line, although there does appear to be a linear relationship of Archie's law form for the samples, indicating the importance of pore-fluid conduction. However, some other mechanism of conduction is reducing the resistivity of the Leg 34 (and 26) samples by a factor of 3 or 4 below the resistivity expected for a particular porosity from the DSDP 2-14 line.

The ratios, dry rock resistivity:seawater-saturated rock resistivity, are given in Table 1, which summarizes the resistivity data. The values range from 4.7 to 46.6 . In contrast, this ratio for 40 subaerial volcanics from the Azores, in which pore-fluid conduction is the dominant mechanism, ranges from $10^{2}$ to $10^{3}$.

These data suggest, therefore, that two conduction mechanisms exist in the ocean-floor samples, both mineral grain semiconduction, from the temperature dependence of resistivity and dry:saturated resistivity ratios, and ionic pore fluid conduction, from the pressure and porosity dependence. Based on the distinct difference in porosity dependence of resistivity between the Leg 2-14 samples (which are generally from only

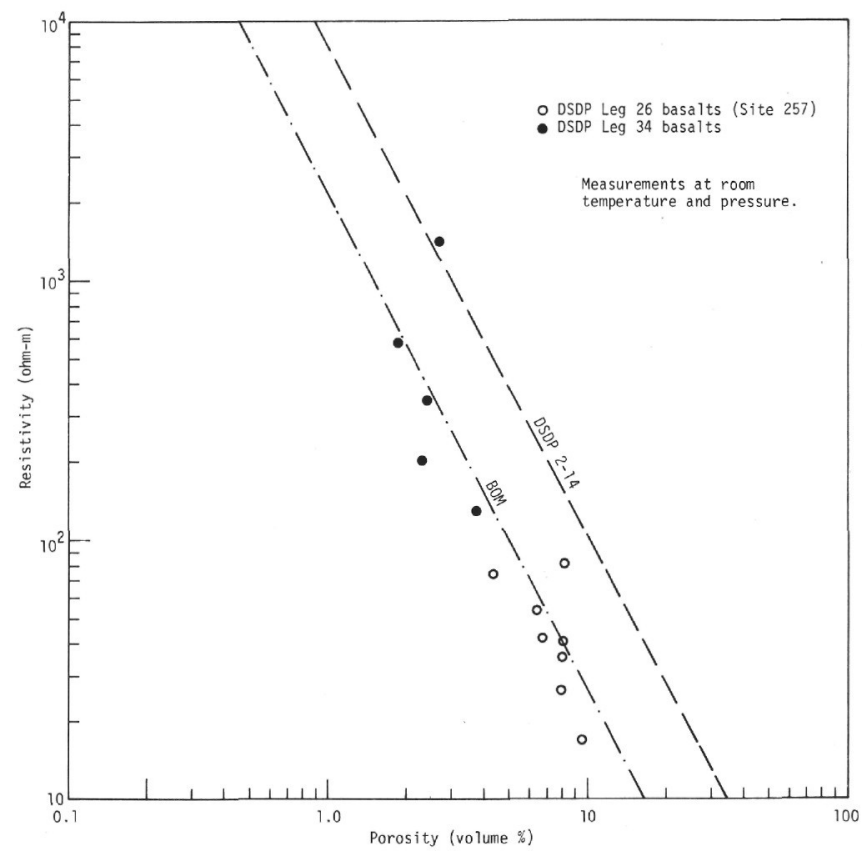

Figure 3. Resistivity versus porosity plot for Leg 34 basalts. Shown for comparison are eight Leg 26 samples from Site 257. The curve "BOM" is from Brace et al. (1965). The curve DSDP 2-14 is the least-squares to fit 25 samples from DSDP Legs 2-6 and 11-14.

very shallow basement penetration of mainly pillow fragments) and the more deeply drilled Leg 34 samples (up to about $60 \mathrm{~m}$ subbasement, representing massive flow interiors) and Leg 26, Site 257, samples (similar basement penetration), the relative importance of the conduction mechanisms appears to be a function of the degree of halmyrolysis (isothermal chemical alteration) and possibly deuteric alteration of the samples. Closer inspection of the mineralogy and alteration products of the near-basement surface pillow lavas and the deeper drilled samples should prove useful in trying to isolate the mineral or minerals responsible for the low observed resistivities of the ocean-floor basalts and indicate why the more weathered basement surface samples should be more resistive at a given porosity than the deeper

TABLE 1

Summary of Resistivity Data for Leg 34 Samples

\begin{tabular}{lcccrc}
\hline Sample & $\begin{array}{c}\rho_{s}(0.5 \mathrm{~kb}) \\
\text { (ohm.m) }\end{array}$ & $\begin{array}{c}\rho_{s}(1 \mathrm{bar}) \\
\text { (ohm.m) }\end{array}$ & $\begin{array}{c}\eta \%^{\mathrm{a}} \\
\text { Total }\end{array}$ & $\rho_{d} / \rho_{s}$ & $E(\mathrm{ev})^{\mathrm{c}}$ \\
\hline $319 \mathrm{~A}-2-1$ & 170 & 128 & 3.75 & 46.6 & 0.27 \\
$321-14-3$ & 265 & 199 & 2.30 & 5.4 & 0.20 \\
$319 \mathrm{~A}-5-1$ & 485 & 355 & 2.40 & 4.7 & 0.27 \\
$319 \mathrm{~A}-3-4$ & 652 & 576 & 1.86 & 8.2 & 0.27 \\
$319 \mathrm{~A}-7-1$ & 1740 & 1425 & 2.64 & 31.6 & 0.27 \\
\hline
\end{tabular}

Note: $\rho_{d}$ is the dry rock resistivity;

$\rho_{s}$ is the seawater-saturated resistivity.

${ }^{\mathrm{a}}$ Total effective porosity at 1 bar pressure.

${ }^{b}$ At 1 bar pressure.

$c_{E}=$ activation energy in electron volts. 
samples. This interpretation of the resistivity data is consistent with current models of sea-floor alteration processes (e.g., Hart, 1973).

\section{REFERENCES}

Boyce, R.E., 1973. Physical properties-methods. In Edgar, N.T., Saunders, J.B., et al., Initial Reports of the Deep Sea Drilling Project, Volume 15: Washington (U.S. Government Printing Office), p. 1115-1127.

Brace, W.F., 1971. Resistivity of saturated crustal rocks to 40 $\mathrm{km}$ based on laboratory measurements. In Heacock, J.G. (Ed.), The structure and physical properties of the earth's crust: Am. Geophys. Union Geophys. Monogr. Ser., v. 14, p. 243-255.

Brace, W.F. and Orange, A.S., 1968. Further studies of the effects of pressure on electrical resistivity of rocks: J. Geophys. Res., v. 73, p. 5407-5420.

Brace, W.F., Orange, A.S., and Madden, T.R., 1965. The effect of pressure on the electrical resistivity of watersaturated crystalline rocks: J. Geophys. Res., v. 70, p. 56695678.

Coster, H.P., 1948. The electrical conductivity of rocks at high temperatures: Roy. Astron. Soc. Mon. Not., Geophys. Suppl., v. 5, p. 193-199.

Christensen, N.I. and Salisbury, M.H., 1972. Sea floor spreading, progressive alteration of layer II basalts, and associated changes in seismic velocities: Earth Planet. Sci. Lett., v. 15, p. 367-375.
Cox, C.S., Filloux, J.H., and Larsen, J.C., 1970. Electromagnetic studies of ocean currents and electrical conductivity below the ocean floor. In Maxwell, A.E., (Ed.), The sea, v. 4: New York (Interscience), p. 637-693.

Greenhouse, J.P., 1972. Geomagnetic time variations on the sea floor off southern California: Unpublished $\mathrm{Ph}$. D. thesis, University of California.

Hamilton, R.M., 1965. Temperature variation at constant pressure of the electrical conductivity of periclase and olivine: J. Geophys. Res., v. 70, p. 5679-5692.

Hart, R.A., 1973. A model for chemical exchange in the basalt-seawater system of oceanic Layer II: Canadian J. Earth Sci., v. 10, p. 799-816.

Hermance, J.F., Nur, A., and Bjornsson, S. 1972. Electrical properties of basalt: relation of laboratory to in situ measurements: J. Geophys. Res., v. 77, p. 1424-1429.

Hyndman, R.D. and Ade-Hall, J.M., 1974. Electrical resistivity of basalts from DSDP Leg 26. In Luyendyk, B.P., Davies, T.A., et al., Initial Reports of the Deep Sea Drilling Project, Volume 26: Washington (U.S. Government Printing Office), p. 505-508.

Keller, G.V., 1966. Electrical properties of rocks and minerals: In Clark, S.P., Jr. (Ed.), Handbook of physical constants: Geol. Soc. Am. Mem. 97, p. 553-577.

Richards, M.L., 1970. A study of electrical conductivity in the earth near Peru: Unpublished Ph. D. thesis, University of California.

Stesky, R.M. and Brace, W.F., 1973. Electrical conductivity of serpentinized rocks to 6 kilobars: J. Geophys. Res., v. 78, p. 7614-7621. 